\title{
How Can We Measure the Effects of Exercise in Daily Life?
}

\author{
Sang Yong Kim \\ Division of Endocrinology and Metabolism, Department of Internal Medicine, Chosun University College of Medicine, Gwangju, Korea
}

Abdominal obesity and insulin resistance are closely related to the pathogenesis of type 2 diabetes [1]. Inadequate diet, but more importantly, decreased activity are important causes of abdominal obesity. Decreased activity and its effects, seen in diabetic patients, as well as the general population, is already a global issue. Adverse effects include abdominal obesity, leading to the development of chronic disease, such as diabetes and hypertension, as well as increases in the risk of cardiovascular and cerebrovascular events [2]. The most important component in treating diabetes is lifestyle modification involving both diet and exercise management. The American Diabetes Association recommends regular exercise for the prevention and treatment of type 2 diabetes, which is also applied in numerous countries, including Korea [3].

Aerobic exercise, known to effectively decrease visceral fat, is the recommended exercise for both obese and non-obese diabetic patients [4]. Gan et al. [5] reported that a 40-minute aerobic exercise 4 - 5 times a week, with a $55-70 \%$ maximal oxygen uptake, significantly reduced visceral fat and also increased cardiopulmonary function. Energy expenditure through aerobic exercise plays an important role in treating and preventing disease related to obesity and is especially important to achieve treatment goals effectively. Many studies have quantified aerobic exercise related to training. However, studies quantifying aerobic exercises in daily life are rare. Therefore, accelerometry is used as an efficient method for quantifying daily energy expenditures and serially measuring the intensity, length, and frequency of physical activity for the purpose of obtaining objective data related to an individual's exercise patterns [6].

In this issue, Kwon et al. [7] used accelerometry in obese type 2 diabetic patients to measure aerobic exercise in daily life and study the differences seen in visceral fat load and muscle strength through aerobic exercise. In the 12-week study comparing the aerobic exercise group to the control group, body mass index and waist circumference decreased. Significant decreases in total abdominal fat, visceral fat, and subcutaneous fat were noted. Total energy expenditure and active energy expenditure showed significant increases. These results coincide with the fact that aerobic exercise is an effective method to decrease visceral fat, which, in turn, implies that aerobic exercise in obese diabetic patients can modify risk factors effectively [6]. Although exercise intensity was not correlated with a decrease in visceral fat, moderate-intensity exercise showed an association with a decrease in total abdominal fat and subcutaneous fat, supporting the previous finding that moderate-intensity exercise is the most beneficial for burning fat in chronic diseases [8]. As the author stated, the patients were randomly assigned to each group, and the total energy expenditure showed no significant difference between the two groups. However, the activity-related energy expenditure was significantly higher in the aerobic exercise group than the control group at baseline. This difference may have led to a significant kitt score and also may influence the results related to the efficacy of aerobic exercise. In a study conducted in a short period, such as this, the energy expenditures prior to the study period may have a direct effect on the results. The absence of data related
Corresponding author: Sang Yong Kim

Department of Internal Medicine, Chosun University Hospital,

Seoseok-dong, Dong-gu, Gwangju 501-717, Korea

E-mail: diabetes@chosun.ac.kr
This is an Open Access article distributed under the terms of the Creative Commons Attribution Non-Commercial License (http://creativecommons.org/licenses/by-nc/3.0/) which permits unrestricted non-commercial use, distribution, and reproduction in any medium, provided the original work is properly cited. 
to $\mathrm{HbA1C}$ or cholesterol profiles prior to and after the study is also a limitation. The improvement of these profiles may be obvious, but this data can also serve as evidence of the changes seen in energy expenditures related to exercise. Despite the limitations, the importance of this study of the changes in cardiopulmonary function and abdominal fat related to aerobic exercise within daily life in obese diabetic patients is paramount. There are many studies related to quantifying aerobic exercise, but most are related to aerobic exercise through training. Therefore, this study may provide a basis for quantifying and systematically approaching diabetic patients with exercise therapy. Finally, I would like to express my gratitude to the authors for such a study and expect further expansion of this study to yield even more useful results.

\section{REFERENCES}

1. Eriksson J, Franssila-Kallunki A, Ekstrand A, Saloranta C, Widén E, Schalin C, Groop L. Early metabolic defects in persons at increased risk for non-insulin-dependent diabetes mellitus. N Engl J Med 1989;321:337-43.

2. Williams MJ, Hunter GR, Kekes-Szabo T, Snyder S, Treuth MS. Regional fat distribution in women and risk of cardiovascular disease. Am J Clin Nutr 1997;65:855-60.

3. Klein S, Sheard NF, Pi-Sunyer X, Daly A, Wylie-Rosett J, Kulkarni K, Clark NG; American Diabetes Association; North American Association for the Study of Obesity; American Society for Clinical Nutrition. A statement of the American Diabetes Association, the North American Association for the Study of Obe- sity, and the American Society for Clinical Nutrition. Weight management through lifestyle modification for the prevention and management of type 2 diabetes: rationale and strategies. Diabetes Care 2004;27:2067-73.

4. Mourier A, Gautier JF, De Kerviler E, Bigard AX, Villette JM, Garnier JP, Duvallet A, Guezennec CY, Cathelineau G. Mobilization of visceral adipose tissue related to the improvement in insulin sensitivity in response to physical training in NIDDM: effects of branched-chain amino acid supplements. Diabetes Care 1997;20:385-91.

5. Gan SK, Kriketos AD, Ellis BA, Thompson CH, Kraegen EW, Chisholm DJ. Changes in aerobic capacity and visceral fat but not myocyte lipid levels predict increased insulin action after exercise in overweight and obese men. Diabetes Care 2003;26: 1706-13.

6. Kumahara H, Schutz Y, Ayabe M, Yoshioka M, Yoshitake Y, Shindo M, Ishii K, Tanaka H. The use of uniaxial accelerometry for the assessment of physical-activity-related energy expenditure: a validation study against whole-body indirect calorimetry. Br J Nutr 2004;91:235-43.

7. Kwon HR, Min KW, Ahn HJ, Seok HG, Koo BK, Kim HC, Han KA. Effects of aerobic exercise on abdominal fat, thigh muscle mass and muscle strength in type 2 diabetic subject. Korean Diabetes J 2010;34:23-31.

8. Lee SH, Lee YS. Comparison of maximal and minimal Fat oxidation exercise intensity and physiological and metabolic variables by treadmill graded maximal exercise test protocols. Korean J Sport Sci 2005;16:42-55. 